\title{
Gonad maturation as an indication of seasonal cycles for several species of small copepods in the Barents Sea
}

\author{
M. FREDRIKA NORRBIN
}

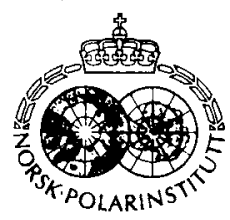

\begin{abstract}
Norrbin, M. F. 1901: Gonad maturation as an indication of scasonal cycles for several species of small copepods in the Barents Sea. Pp. 421-432 in Sakshaug. E., Hopkins. C. C. E. \& Øritsland, N. A. (cds.): Proceedings of the Pro Mare Symposium on Polar Marine Ecology, Trondheim, 12-16 May 1990. Polar Reserch 10(2).

In a remote oceanic area like the Barents Sca, it is often difficult to follow the seasonal development of copepod populations in detail. Information on the gonad maturation stage of older juveniles and adults of a species will reveal the immediate state of reproduction and the expected development of juveniles into reproductively active adults. Winter "resting stages" in juveniles can also be recognised.

Zooplankton were caught during Pro Mare cruises in carly March, May, July/August, mid-Scptember and mid-October. Abundance and composition of developmental stages of small copepods were determined for several stations from each cruise. Samples consisting of Stages CIV to CVI of Pseudocalanus acuspes (Giesbrecht 1881), P. minutus (Kröyer), Microcalanus pusillus (Sars), and M. pygmaeus Sars were stained with carmine and analysed with respect to gonad maturation stage. length, width, and area of the prosome and the area of the gonad and the oil sac. Image analyses were performed from photographs or drawings of copepods using a digitising pad.

With additional information on abundance and stage composition, and by comparing the present data set with information on Pseudocalanus spp. from Balsfjorden, northern Norway, seasonal cycles for the species could be inferred.
\end{abstract}

Fredrika Norrbin, Department of Aquatic Biology, The Norwegian College of Fishery Science. P.O. Box 3083 Guleng, N-9001 Tromsø. Norway (revised February 1991).

\section{Introduction}

In Arctic and subarctic areas, where the yearly input from primary production to higher trophic levels is typically limited in time, the dominant species of large, herbivorous copepods are known to be active during only part of the year (Hopkins et al. 1984; Tande et al. 1985). They produce one or less than one generation per year and spend most of the time either building up energy stores or in a resting state, slowly consuming these reserves.

The many smaller species of copepods have been described in several studies of high latitude zooplankton (e.g. Ussing 1938; Digby 1954; Fontaine 1955; Grainger 1959; McLaren 1969). Although numerically dominating in nearshore Arctic areas (Horner \& Murphy 1985), the small species have lately been found to be of little importance in offshore ecosystems (e.g. Cooney \& Coyle 1982; Vidal \& Smith 1986). However, many of the recent studies have been conducted primarily during the spring and summer seasons, while high abundances of small copepods have been recorded mainly during the second half of the year (Minoda 1967; Hassel 1986; the present study). In many cases the nets used have been too coarse to catch young stages of Microcalanus in particular. This suggests that smaller species may still play an important role in Arctic food webs during autumn and winter.

Gonad maturation has been used to describe life cycles for large, herbivorous copepods and some smaller species in Balsfjorden, Northern Norway (Tande \& Hopkins 1981; Tande \& Grönvik 1983; Norrbin 1987) and in the Barents Sea (Tande et al. 1985). Experimental work with a small copepod from temperate areas shows that the gonads of juveniles grow larger under good feeding conditions (Razouls et al. 1987). This is reflected in seasonal cycles in gonad size and maturation of Pseudocalanus in Balsfjorden (Norrbin 1987). In Balsfjorden, the drop in gonad 
size of juvenile Pseudocalanus in late summer anticipates the beginning of the overwintering resting period long before signs of this are visible in other factors (Norrbin 1987; unpubl. data).

During the latter part of the Pro Mare programme, some of the cruises took place during autumn and winter, enabling the study of biologial material from the "unproductive" season. The aim of this project within Pro Mare has been to evaluate the importance of the smaller species of calanoid copepods in the Barents Sea ecosystem, with an emphasis on their significance during the time when larger calanoids are inactive. In this paper information on stage composition and gonad maturation is used to infer seasonal life cycles for four copepod species; Pseudocalanus acuspes, $P$. minutus, Microcalanus pusillus, and M. pygmaeus.

\section{Materials and methods}

Plankton was sampled during the Pro Mare cruises of 1987 and 1988; Cruise 11 in March 1987, Cruise 13 in October 1987, Cruise 14 in May 1988, and Cruise 16 in September 1988 (Fig. 1). Additional samples derive from Cruise 2 in JulyAugust 1984 (Fig. 1). The region covered by sampling typically consisted of latitudinal transects into the ice edge followed by a number of stations in ice-covered waters.

Sampling equipment usually consisted of $90 \mu \mathrm{m}$ WP-2-nets. On Cruise 12, a $200 \mu \mathrm{m}$ WP-2 net was used and on Cruise 10, a $90 \mu \mathrm{m}$ Juday net (for a description of the nets, see e.g. Unesco 1968). Zooplankton was concentrated and preserved in a solution of $4 \%$ formaldehyde and $5 \%$ propylene glycol immediately upon sampling. This was exchanged for a weaker preservative upon return to the laboratory.

Stage and sex composition of small copepod species were estimated from subsamples. A minimum of 1000 individuals were counted from each station.

Gonad maturation of males and females of copepodite Stages IV to $\mathrm{V}$ was analysed for the species Pseudocalanus acuspes (Giesbrecht, 1881; see Frost 1989), P. minutus (Kröyer), Microcalanus pusillus (Sars), and $M$. pygmaeus Sars (Fig. 2).

(The genus Microcalanus is currently subject to some taxonomic confusion. The species in this study have been determined as far as possible

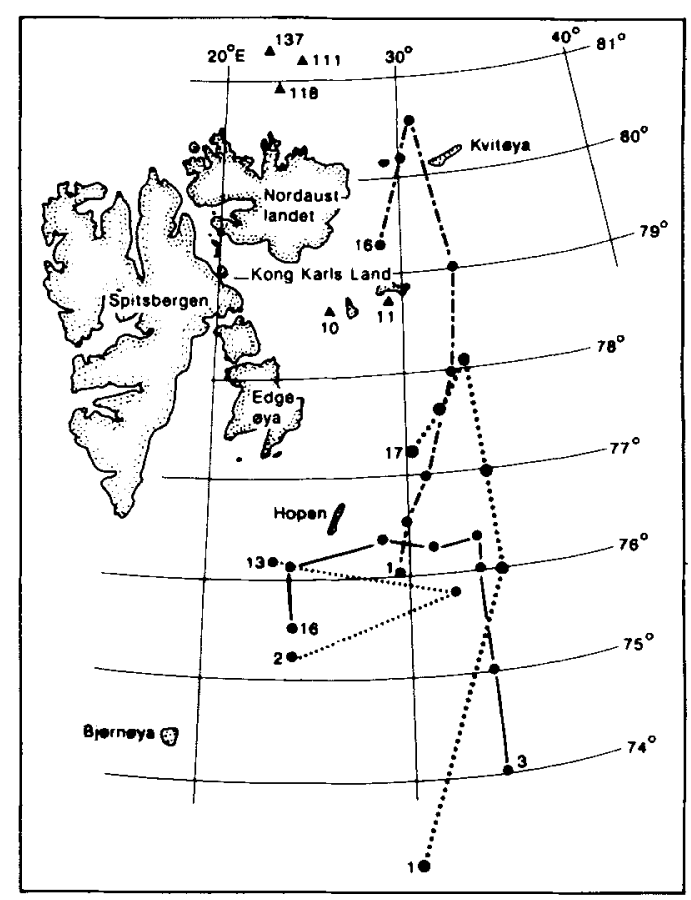

Fig. I. The western Barents Sea. Stations from Pro Mare cruises. Starting and end stations are indicated, the lines connecting the stations signify different cruises; small dots $=$ Cruise 10 ; larger dots $=$ Cruise 13: unbroken line $=$ Cruise $14:$ lines and dots $=$ Cruise 16. In addition, stations from Cruise 2 relevant for this study are denoted by triangles.

according to Sars (1903), Brodskii (1950) and Vidal (1971). Occasional specimens of Microcalanus sp. $b$ were found in the samples (Vidal 1971)).

There was a great variation in the abundance of different species and developmental stages in samples from different stations and seasons. The aim was to analyse at least 20 copepods of any given stage and sex from each station, but this was often not possible.

Copepods were stained in ethanolic borax carmine for several days, then rinsed in distilled water, dehydrated in ethanol and finally transferred to cedar wood oil (Norrbin 1987). Groups of stained copepods were arranged in a lateral position in cedar wood oil on a glass slide (Figs. 2 and 3 ). They were then photographed through a Wild Heerbrugg dissecting microscope. The resulting colour slides were projected down on a CalcComp 2500 digitising pad. Several measurements were taken (see below) and fed directly into a computer file using a specially adapted 
A

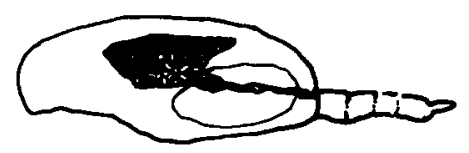

B

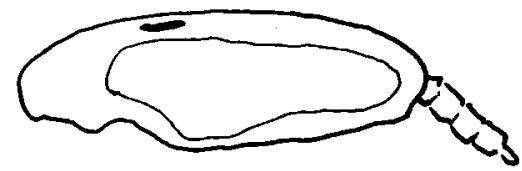

$\mathrm{C}$

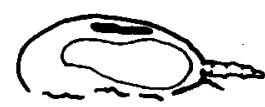

$\mathrm{D}$

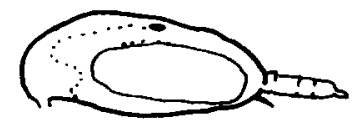

0

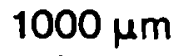

Fig. 2. Species in the present study, appearance of stained copepods. The figure shows prosome and urosome in lateral view. A. Pseudocalanus acuspes $\mathrm{CV}$ female in advanced state of maturation. B. P. minutus $\mathrm{CV}$ female in gonad resting state. C. Microcalanus pusillus CV male with medium-sized gonad. D. $M$. pygmaeus $\mathrm{CV}$ male in gonad resting state.

Basic programme which calculated distances and areas. A small number of the copepods were drawn on paper using a camera lucida instead of photography. These were digitised in the same way as above.

The measurements taken were prosome length and greatest width, area of prosome, area of gonad, and area of oil sac (Fig. 3). Simul-

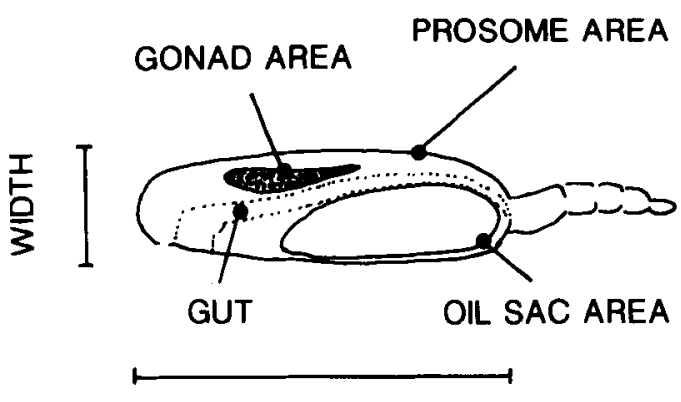

\section{LENGTH}

Fig. 3. Measurements taken on copepods using digitising table.

taneously, notes were made of gonad maturation stage (after Corkett \& McLaren 1978; Tande \& Hopkins 1981; Norrbin 1987).

Analysis of the data was performed using Microsoft Excel spreadsheets and Statgraphics Statistical Graphics System, Version 3.0.

\section{Results}

\section{Species composition}

All four species in this study co-occurred on stations in the western Barents Sea (Table 1). There was a tendency for Pseudocalanus to be dominant in shallow areas and for Microcalanus to be more dominant in water of more than $200 \mathrm{~m}$ depth (Table 1).

Abundances were generally higher in the southern part of the investigated area and copepod numbers increased during the year, reaching a maximum in September and October (Table 1).

\section{Stage distribution}

Some features of the stage distributions of all copepod species in the present study are especially noteworthy; presence of adult females indicates ongoing or recently ceased reproduction, and presence of adult males indicates that mating and reproduction have recently begun. A large number of early copepodites (CI) is a sign of recent reproductive activity and ongoing development of the population. McLaren (1974) and Corkett \& McLaren (1978) give a development time from egg to CI of approximately 45 days at $0^{\circ} \mathrm{C}$ for Pseudocalanus). Absence of the youngest stages and a predominance of CIII to CV imply an accumulation of overwintering stages.

Because stage distribution varied between regions, the figures representing this distribution are divided into five areas (Figs. 4 to 7): Atlantic Water north and south of approximately $76^{\circ} \mathrm{N}$, Polar Water north and south of approximately $79^{\circ} \mathrm{N}$, and shallow areas at 75 to $77^{\circ} \mathrm{N}$ (on Spitsbergenbanken or Hopenbanken), usually with mixed water masses. Representative stations from each sampled region are shown for March, May, September, and October (Figs. 4 to 7; Table 1). Northerly Atlantic Water stations and southerly Polar Water stations overlap due to the fluctuation of the position of the Polar Front. Most stations were localised in the marginal ice zone, 
Table 1. Zooplankton sampling data for the Pro Mare cruises and abundance of small copepods. "Region" refers to regional divisions used in Figs. 4 to 7. P.a. $=$ Pseudocalanus acuspes. P.m. $=$ P. minurus, M.pu. $=$ Microcalanus pusillus, M.py. $=M$. pygmaeus. Total $=$ total small copepods including Cyclopoida and Harpacticoida. A plus sign signifies an abundance of less than one individual per cubic meter.

\begin{tabular}{|c|c|c|c|c|c|c|c|c|c|c|}
\hline \multirow[b]{2}{*}{ Date } & \multirow[b]{2}{*}{ Station } & \multirow[b]{2}{*}{ Region } & \multirow{2}{*}{$\begin{array}{l}\text { Position } \\
\text { Lat }\end{array}$} & \multirow[b]{2}{*}{ Long } & \multirow{2}{*}{$\begin{array}{l}\text { Depth } \\
(\mathrm{m})\end{array}$} & \multicolumn{5}{|c|}{ Abundance of small copepods (individuals $\mathrm{m}^{-2}$ ) } \\
\hline & & & & & & P.a. & P.m. & M.pu. & M.py. & Total \\
\hline \multicolumn{11}{|c|}{ Cruise 2, 1984} \\
\hline $21 \mathrm{Jul}$ & 11 & - & $78^{\circ} 48^{\prime} \mathrm{N}$ & $28^{\circ} 19^{\prime} \mathrm{E}$ & 30 & 0 & 490 & 0 & 0 & 833 \\
\hline 01 Aug & 111 & - & $80^{\circ} 12^{\prime} \mathrm{N}$ & $24^{\circ} 16^{\prime} \mathrm{E}$ & 195 & 23.121 & 1,861 & 9,013 & 392 & 54,766 \\
\hline 01 Aug & 118 & - & $80^{\circ} 52^{\prime} \mathrm{N}$ & $23^{\circ} 00^{\prime} \mathrm{E}$ & 55 & 98 & 11.757 & 0 & + & 28.412 \\
\hline 01 Aug & 137 & - & $81^{\circ} 18^{\prime} \mathrm{N}$ & $22^{\circ} 20^{\prime} \mathrm{E}$ & 220 & - & - & - & - & - \\
\hline 06 Aug & 160 & - & $79^{\circ} 40^{\prime} \mathrm{N}$ & $26^{\circ} 26^{\prime} \mathrm{E}$ & 150 & 6.369 & 18.693 & 2.492 & + & 46.663 \\
\hline \multicolumn{11}{|c|}{ Cruise 10,1987} \\
\hline $01 \mathrm{Mar}$ & 2 & $\mathrm{C}$ & $75^{\circ} 16^{\prime} \mathrm{N}$ & $23^{\circ} 31^{\prime} \mathrm{E}$ & 114 & 38.270 & 2.246 & 8,630 & + & 109,134 \\
\hline 02 Мат & 6 & $\mathrm{D}$ & $75^{\circ} 49^{\prime} \mathrm{N}$ & $30^{\circ} 04^{\prime} \mathrm{E}$ & 325 & 5.931 & 4.397 & 34.200 & 614 & 243,645 \\
\hline $06 \mathrm{Mar}$ & 13 & $\mathrm{C}$ & $76^{\circ} 11 ' \mathrm{~N}$ & $22^{\circ} 51^{\prime} \mathrm{E}$ & 48 & 25.134 & 982 & 82 & + & 29,882 \\
\hline \multicolumn{11}{|c|}{ Cruise 13, 1987} \\
\hline $15 \mathrm{Oct}$ & 1 & $\mathrm{E}$ & $73^{\circ} 10^{\prime} \mathrm{N}$ & $27^{\circ} 58^{\prime} \mathrm{E}$ & 320 & 0 & + & 27,840 & 0 & 127.069 \\
\hline $16 \mathrm{Oct}$ & 5 & $\mathrm{D}$ & $76^{\circ} 00^{\prime} \mathrm{N}$ & $32^{\circ} 10^{\prime} \mathrm{E}$ & 320 & 15.971 & 10.394 & 246.493 & 9,328 & $1,470,505$ \\
\hline $16 \mathrm{Oct}$ & 7 & - & $77^{\circ} 00^{\prime} \mathrm{N}$ & $32^{\circ} 00^{\prime} \mathrm{E}$ & 210 & 12.015 & 11.348 & 60,744 & 5,340 & 580.742 \\
\hline $20 \mathrm{Oct}$ & 12 & B & $78^{\circ} 01^{\prime} \mathrm{N}$ & $31^{\circ} 41^{\prime} \mathrm{E}$ & 204 & 1.492 & 1,014 & 457 & 477 & 9.228 \\
\hline $22 \mathrm{Oct}$ & 15 & B & $77^{\circ} 40^{\prime} \mathrm{N}$ & $30^{\circ} 20^{\prime} \mathrm{E}$ & 208 & 88,130 & 16,811 & 10,443 & 225 & 326.286 \\
\hline $24 \mathrm{Oct}$ & 17 & $\mathrm{C}$ & $77^{\circ} 15^{\prime} \mathrm{N}$ & $29^{\circ} 00^{\prime} \mathrm{E}$ & 187 & 2.738 & 573 & 1.592 & + & 28,146 \\
\hline \multicolumn{11}{|c|}{ Cruise 14, 1988} \\
\hline 21 May & 3 & $E$ & $74^{\circ} 00^{\prime} \mathrm{N}$ & $31^{\circ} 13^{\prime} \mathrm{E}$ & 279 & 300 & 1,502 & $82 .(128$ & 601 & 232,864 \\
\hline $21 \mathrm{May}$ & 5 & $E$ & $75^{\circ} 00^{\prime} \mathrm{N}$ & $31^{\circ} 13^{\prime} \mathrm{E}$ & 358 & 1.307 & 980 & 8,479 & + & 213,115 \\
\hline $21 \mathrm{May}$ & 6 & $\mathrm{D}$ & $76^{\circ} 03^{\prime} \mathrm{N}$ & $31^{\circ} 09^{\prime} \mathrm{E}$ & 335 & 1,085 & 1.883 & 12,673 & 1.199 & 214.836 \\
\hline 22 May & 7 & $\mathrm{D}$ & $76^{\circ} 22^{\prime} \mathrm{N}$ & $31^{\circ} 03^{\prime} \mathrm{E}$ & 304 & 505 & 842 & 11.765 & 787 & 172.019 \\
\hline $23 \mathrm{May}$ & 9 & $\mathrm{D}$ & $76^{\circ} 16^{\prime} \mathrm{N}$ & $29^{\circ} 17^{\prime} \mathrm{E}$ & 241 & 557 & 658 & 5,509 & 692 & 125,871 \\
\hline 24 May & 10 & B & $76^{\circ} 25^{\prime} \mathrm{N}$ & $27^{\circ} 11^{\prime} \mathrm{E}$ & 91 & 1,258 & 802 & 350 & + & 27,003 \\
\hline 27 May & 13 & C & $76^{\circ} 10^{\prime} \mathrm{N}$ & $23^{\circ} 25^{\prime} \mathrm{E}$ & 42 & 4.832 & 392 & 0 & 0 & 8.687 \\
\hline 30 May & 16 & $\mathrm{C}$ & $75^{\circ} 29^{\prime} \mathrm{N}$ & $23^{\circ} 31^{\prime} \mathrm{E}$ & 85 & 133 & 333 & 2.332 & 100 & 9.260 \\
\hline \multicolumn{11}{|c|}{ Cruise 16,1988} \\
\hline 09 Sep & 1 & C & $76^{\circ} 00^{\prime} \mathrm{N}$ & $28^{\circ} 00^{\prime} \mathrm{E}$ & 167 & 10,369 & 8.791 & 7.664 & 676 & 664,957 \\
\hline 10 Sep & 3 & - & $76^{\circ} 34^{\prime} \mathrm{N}$ & $28^{\circ} 28^{\prime} \mathrm{E}$ & 72 & 144,210 & 23.739 & + & + & 456.158 \\
\hline 10 Sep & 4 & $\mathrm{D}$ & $77^{\circ} 00^{\prime} \mathrm{N}$ & $29^{\circ} 26^{\prime} \mathrm{E}$ & 232 & 53.897 & 9,503 & 13,640 & 638 & $2,000,267$ \\
\hline 11 Sep & 6 & B & $78^{\circ} 00^{\prime} \mathrm{N}$ & $31^{\circ} 01^{\prime} \mathrm{E}$ & 233 & 2.871 & 269,810 & 1,816 & 306 & $1,631,141$ \\
\hline 11 Sep & 8 & - & $79^{\circ} 06^{\prime} \mathrm{N}$ & $31^{\circ} 56^{\prime} \mathrm{E}$ & 80 & 16,332 & 29.705 & 0 & 157 & 177,806 \\
\hline 13 Sep & 12 & A & $80^{\circ} 33^{\prime} \mathrm{N}$ & $30^{\circ} 28^{\prime} \mathrm{E}$ & 207 & 27.269 & 13.639 & 9,471 & 2,567 & 148,026 \\
\hline $14 \mathrm{Sep}$ & 13 & A & $80^{\circ} 12^{\prime} \mathrm{N}$ & $29^{\circ} 42^{\prime} \mathrm{E}$ & 215 & 26.742 & 8,413 & 9.915 & 3,906 & 182.986 \\
\hline 17 Sep & 16 & - & $79^{\circ} 23^{\prime} \mathrm{N}$ & $28^{\circ} 05^{\prime} \mathrm{E}$ & 311 & 54.055 & 11.605 & 11.146 & 2,266 & 193,279 \\
\hline
\end{tabular}

but the southernmost stations of each cruise were usually set up in open water: stations one to seven of Cruise 13 , one to six of Cruise 14, and stations one to six of Cruise 16. During Cruise 2 all stations except no. 111 were localised in open water.

\section{Pseudocalanus acuspes}

In March the population of $P$. acuspes was still dominated by overwintering copepodites (CIII to $\mathrm{CV}$; Fig. 4). In May the population was in a developing phase at most stations, as evidenced by the presence of $\mathrm{CI}(20$ to $40 \%)$ and older juvenile stages (Fig. 4). The shallow water stations (Fig. 4C) where adults dominated were an exception. In these areas there were high densities of Cirripedia nauplii which may have preyed on young copepodite stages. The southernmost, open water station (Fig. 4E) had the highest number of young copepodites. In July/August there seemed to be developing populations of $P$. acuspes at stations to the west of Nordaustlandet. North of Svalbard the populations were either in a developing phase or dominated by older juveniles. In September, there was a clear predominance of early copepodites in most areas (Fig. 4A, C and D). Very few older copepodites and adults were present, except for a lingering population of adult females at the southerly polar water stations (north of $77^{\circ} \mathrm{N}$; Fig. 4B). The Stage III copepodites may have represented the build- 
<smiles>[Al]=[W]=[V]</smiles>
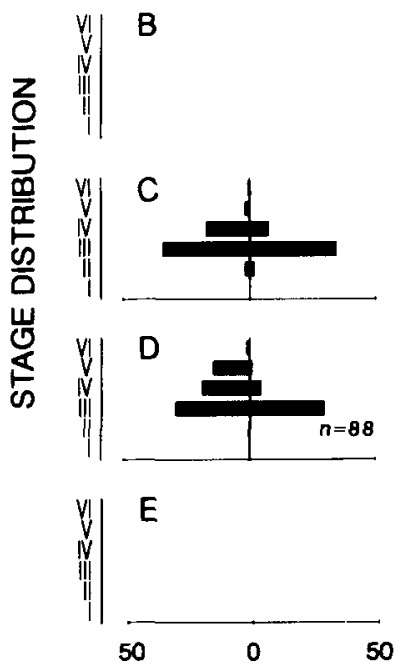

MARCH
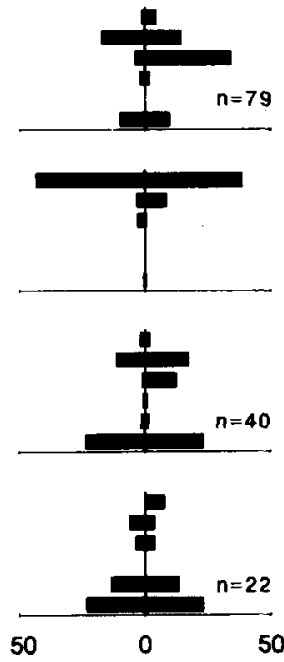

MAY
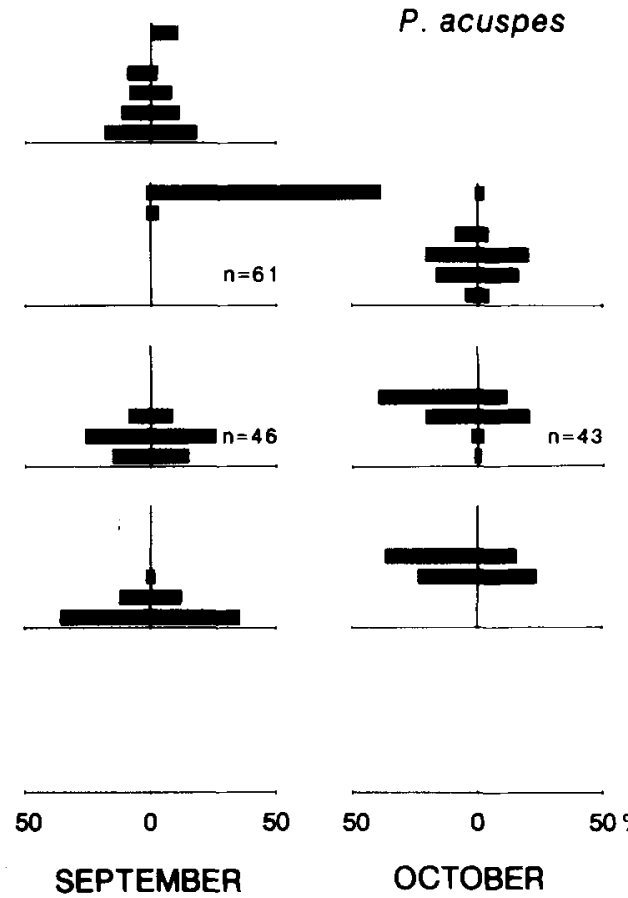

Fig. 4. Seasonal stage distributions for Pseudocalanus acuspes. The presentation is divided into several geographical areas (from north to south): A. $79-81^{\circ} \mathrm{N}$, Polar Water. B. $76-78^{\circ} \mathrm{N}$. Polar Water. C. $75-77^{\circ} \mathrm{N}$, shallow (bank) areas with polar or mixed water. D. $76-77^{\circ} \mathrm{N}$, Atlantic Water. E. $73-75^{\circ} \mathrm{N}$, Atlantic Water. Distributions are given as percentages of all copepodites. Females are placed to the right of the vertical bar and males to the left (sex was determined for copepodite Stages IV to VI). Each distribution represents one to three similar stations. See Table 1, "Region" column, for information on stations used in the construction of this figure. Where a distribution is based on less than 100 copepodites, the number is given in the figure.<smiles>[Al]=[W]=C=[V]</smiles>

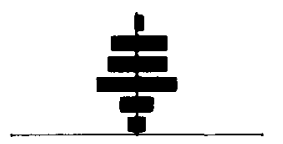

P. minutus
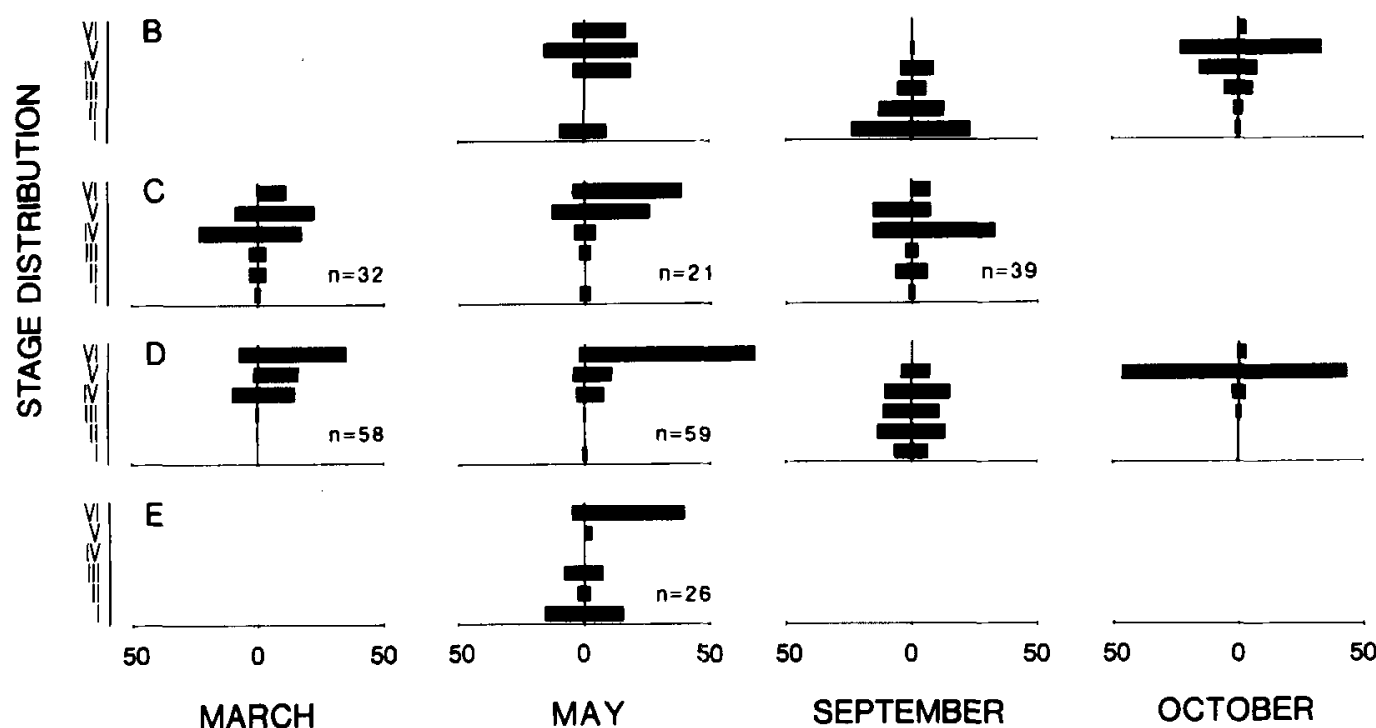

MARCH

MAY
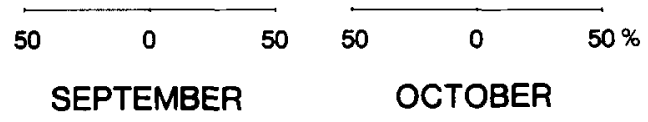

Fig. 5. Scasonal stage distributions for Pseudocalanus minutus. See Fig. 4 for clarification. 


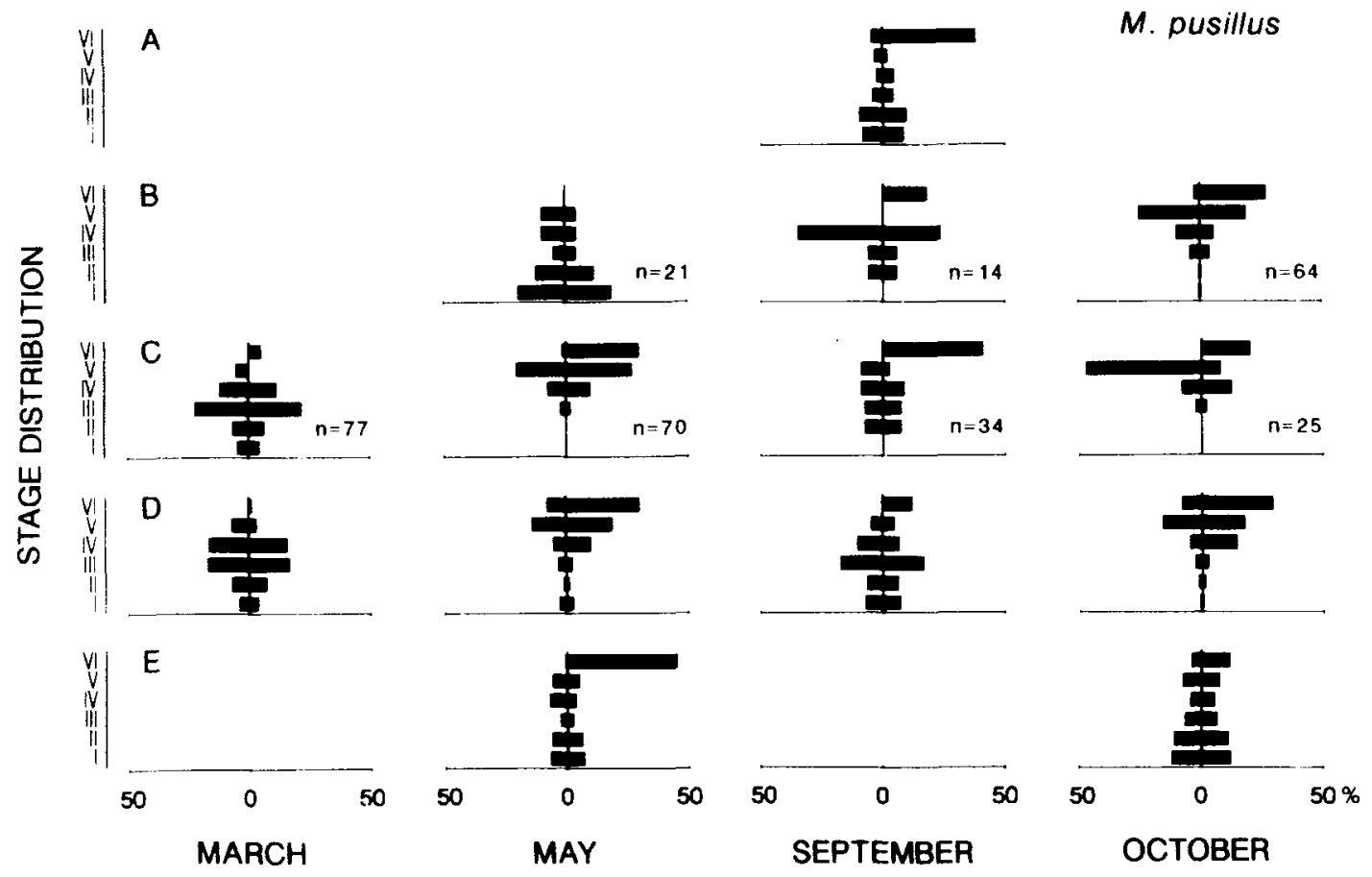

Fig. 6. Seasonal stage distributions for Microcalanus pusillus. See Fig. 4 for clarification.

up of the overwintering population. No adult males were present. In October early copepodites were still present, but the adults had disappeared (Fig. 4).

\section{Pseudocalanus minutus}

In March adult females of $P$. minutus were present at several stations (Fig. 5). Copepodite Stages II and III at these stations may have represented reproduction earlier in the winter or part of the overwintering population. In May there was a dominance of adults and older juveniles at all stations (Fig. 5). As in P. acuspes, the highest concentrations of younger copepodites were found at the most southerly station (Fig. 5E). In July/August the situation was similar to that of $P$. acuspes. In September the accumulation of overwintering stages had proceeded further than for $P$. acuspes, with 50 to $70 \%$ of the population consisting of copepodite Stages III to V. As in $P$. acuspes, there were no adult males, but adult females were still present at northerly stations (Fig. 5A). In October the dominance of overwintering stages was almost total (Fig. 5). There were, however, females present at the north- ernmost stations (Fig. 5B), where grazing seemed to occur.

\section{Microcalanus pusillus}

In March all stages of $M$. pusillus except aduit males were present, suggesting that reproduction had taken place earlier in the winter (Fig. 6C and D). All developmental stages were found at most stations in May (Fig. 6), but at shallow water stations adults and older juveniles dominated (Fig. 6C). In July/August populations seemed to consist largely of adult females, but the younger copepodites are likely to have slipped through the $200 \mu \mathrm{m}$ net because $\mathrm{CI}$ to CIII of this species measure no more than 200 to $340 \mu \mathrm{m}$ in prosome length. In September the younger copepodite stages comprised 10 to $30 \%$ of the populations (Fig. 6). Adult females were abundant especially in areas influenced by Polar Water (Fig. 6A, B and $C$ ) and adult males were present on the northernmost stations (Fig. 6A). All developmental stages were still present in October, but older juveniles and adults predominated (Fig. 6). Adult males were present at most stations. 


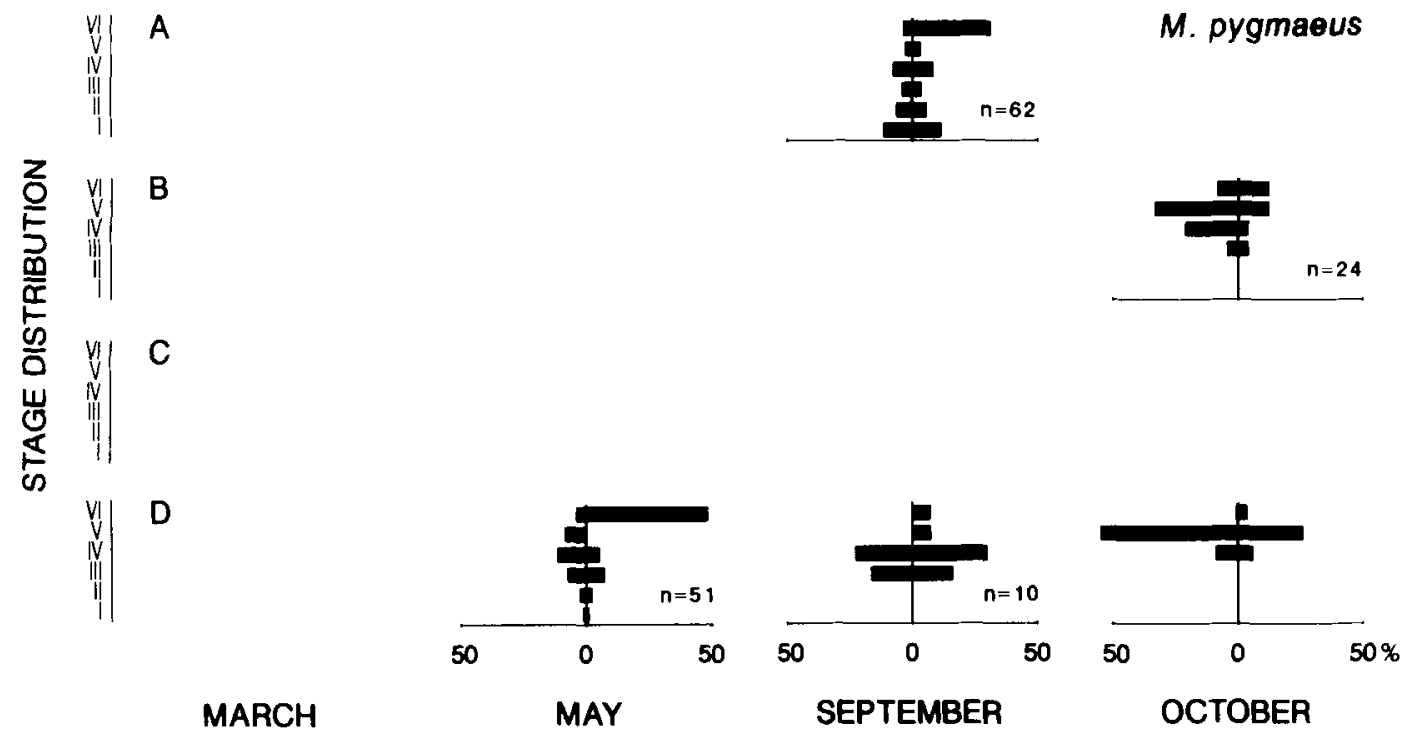

Fig. 7. Seasonal stage distributions for Microcalanus pygmaes. Sec Fig. 4 for clarification.
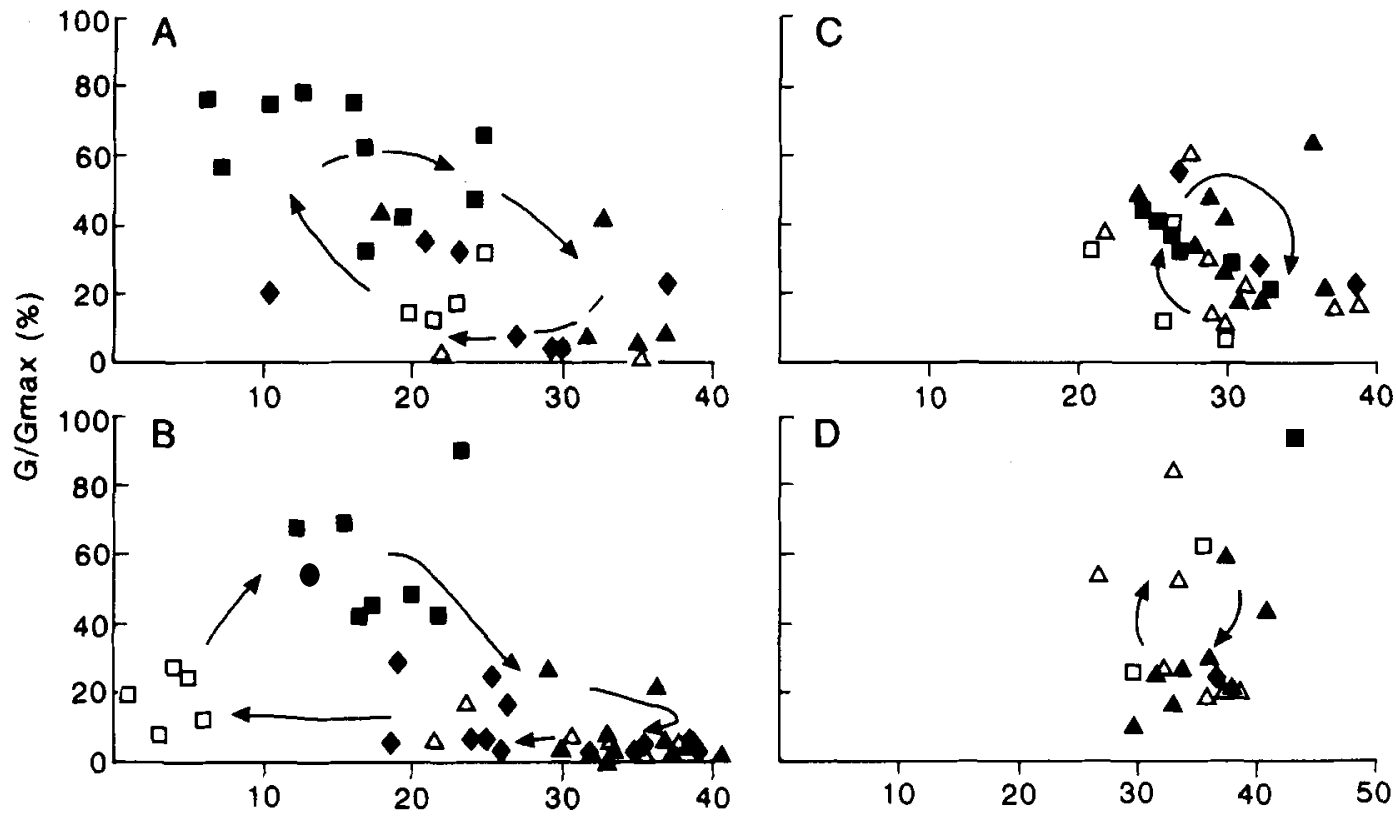

Oil sac index

Fig. 8. Seasonal variations in gonad size and oil content. Station averages for CIV females, CIV males. CV females and CV males. Oil sac index $=$ oil sac area as percentage of prosome area. $G / G_{\max }=$ Gonad area as percentage of maximum observed gonad area in the specific copepodite stage and sex. Open squares = March. solid squares = May, diamonds = July $/$ August, solid triangles $=$ September, and open triangles $=$ October. Arrows show the seasonal cycle of resource allocation to either gonads or oil. A. Pseudocalanus acuspes, B. P. minutus. C. Microcalanus pusillus. D. M. pygmaeus. 


\section{Microcalanus pygmaeus}

In May the stage distribution of $M$. pygmaeus was similar to that of $M$. pusillus (Fig. 7). In September, stage distribution at most stations resembled that of $P$. minutus, with a dominance of older copepodites and adult females (Fig. 7A and D). Some adult males were present. indicating that the populations were not completely "at rest". In October, older juveniles made up from 60 to $100 \%$ of the populations, but adult males were still present at Polar Water stations (Fig. 7B). Very few specimens were found in the March and July/August samples.

\section{Seasonal variation in gonad size and oil content}

Seasonal cycles of energy allocation were evident in stages CIV to CV of all four species (Fig. 8). In May, when gonad sizes were at their maximum. the copepods contained little oil. Oil content increased and gonad size decreased as the season progressed. Maximum oil sac sizes were attained in September for all species. Minimum sizes in gonads were found from September to October for Pseudocalanus acuspes and Microcalanus pygmaeus, from August to September for $P$. minutus, and in October or March for $M$. pusillus.

In $P$. acuspes $\mathrm{CIV}$ and $\mathrm{CV}$ gonad sizes reached a maximum in May (Fig. 8A). At the same time, oil content reached a minimum in this species. In September, copepodites from the northernmost stations tended to have smaller gonads than those from stations further south. Gonads of $P$. minutus copepodites reached their greatest size in May (Fig. 8B) but were large in some localities both in early August and in mid-September (late summer situations).

In early March, gonads increased in size while oil content decreased in all species except $M$. pusillus (Fig. 8A and B). In P. acuspes CIV, but not in $C V$, gonads were larger in March than in the period September/October, indicating the start of spring maturation in the overwintering generation. In $P$. minutus Stage V copepodites also displayed this sign of early maturation in March. Oil stores were nearly depleted in this species in March (Fig. 8B).

The seasonal cycles in both gonad size and oil content were much less-pronounced in the Microcalanus species (Fig 8C and D). Copepodites from May, September and October exhibited some large gonads but also smaller and

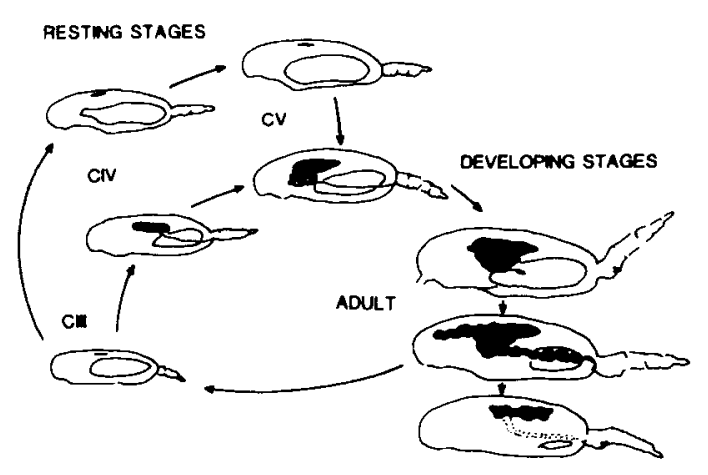

Fig. 9. Life cycle and gonad development of a small calanoid copepod. Inner pathway represents direct development during productive season. Resting stages usually consist of CIV-CV (Pseudocalanus acuspes also CIII) and are formed before winter. In winter-early spring these stages enter the cycle of normally moulting and maturing copepodites.

less mature ones. Only in March were gonads consistently small.

\section{Discussion}

\section{Seasonal cycles in maturation}

The results presented here indicate trends in gonad maturation and in the population development of small copepods. More frequent sampling is needed in order to describe seasonal cycles in detail. It is obvious from earlier studies that small, undeveloped gonads can be used to identify resting copepodites, and that gonads in copepodites during the productive season always appear in a wide size range with a predominance of larger size groups (Fig. 9; Norrbin 1987; unpubl. data). The size increase in gonads of female copepodites is due to the prolongation of the gonad into forward diverticulae and to maturation and migration of oocytes. Razouls et al. (1987) showed that gonads of CV females of Temora stylifera grew more in size under good food conditions. This should lead to efficient utilisation of abundant food regimes, allowing for early maturation and reproduction in the adult stage. In May and August several specimens of Pseudocalanus CV females had ova in their oviducts. In male CV the reproductive system could also be well differentiated, with a visible sperm sac and spermatheca.

It is likely that the seasonal cycles of the Pseudocalanus species in the souhern parts of the 


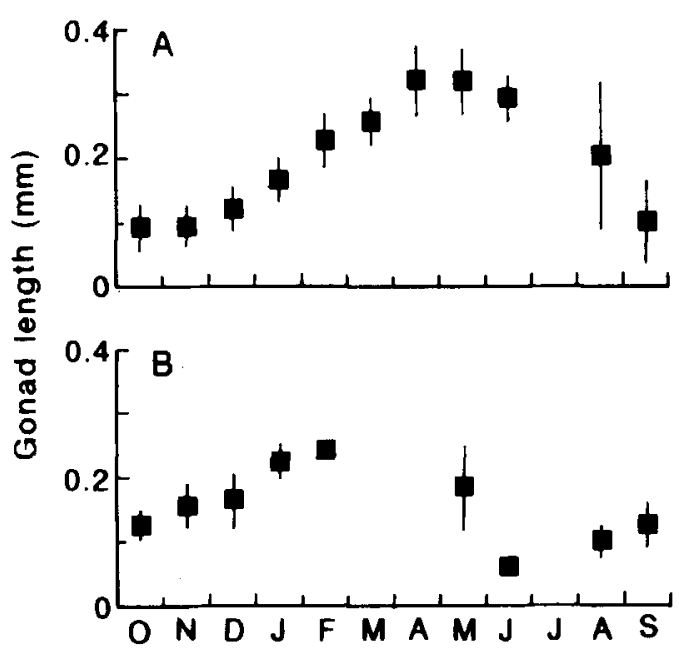

Fig. 10. Seasonal cycle in gonad size for $\mathrm{CV}$ females from Balsfjorden, Northern Norway 1985-86. Gonad size was measured as gonad length. A. Pseudocalanus acuspes. B. P. minutus. Data modified from Norrbin (unpubl. data).

Barents Sea $\left(72\right.$ to $\left.76^{\circ} \mathrm{N}\right)$ are simjlar to those in Balsfjorden $\left(69^{\circ} 30^{\prime} \mathrm{N}\right)$. In the northern areas, which are ice-covered most of the year, there is likely to be a shorter productive period, which results in fewer generations per year. The seasonal variation in gonad length for Pseudocalanus acuspes and $P$. minutus $\mathrm{CV}$ females in Balsfjorden (Fig. 10), together with monthly analyses of stage composition, indicates three generations of $P$. acuspes and two generations of $P$. minutus per year in this area (Norrbin 1987). Overwintering CV females of $P$. acuspes mature between March and April; the first new generation of the year matures in May and there is a second generation which matures in July before the build-up of the new overwintering population begins in August (Fig. 10A; Norrbin 1987). The overwintering generation of $P$. minutus matures in the February-March period and $\mathrm{CV}$ copepodites disappear until May (Norrbin unpubl.; Fig. 10B). The first generation matures in May and from June onwards the overwintering generation is formed, with gonads slowly developing during autumn and winter (Fig. 10B). This pattern is closer to that of the larger copepod Calanus finmarchicus in this area (Tande \& Hopkins 1981).

Similar presentations of gonad size are given for $\mathrm{CV}$ females of the four species in the present study (Fig. 11). Since gonad length was not measured here, and area is proportional to length squared, the square root of the gonad area measurement has been used in Fig. 11. A constant relating area and length is lacking, giving lower values for the Barents Sea copepods (Fig. 11). The Barents Sea data for the Pseudocalanus species imply similar cycles. For $P$. acuspes the stage composition and state of maturation of overwintering juveniles were almost identical in the Barents Sea and Balsfjorden in early March (Figs. $4,10 \mathrm{~A}$ and $11 \mathrm{~A}$; Norrbin 1987). In May there is an obvious maturation of the first generation (Fig. 11A). It is likely that two to three generations of
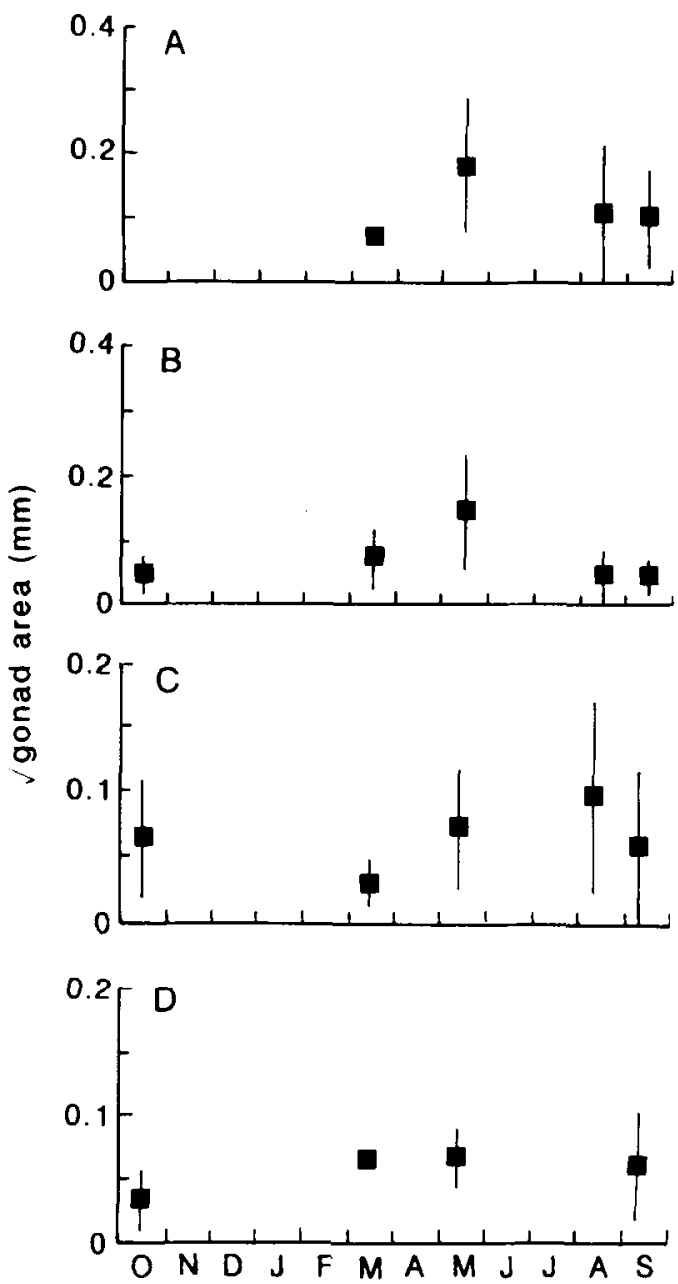

Fig. 1I. Seasonal cycle in gonad size for $\mathrm{CV}$ females from the Barents Sea (present study). Gonad sizes were measured as gonad areas. The square root of this measurement was taken to approximate a length measurement; due to lack of a scaling constant these values are smaller than in Fig. 10A. A. Pseudocalanus acuspes. B. P. minutus. C. Microcalanus pusillus. D. M. pygmaeus 
this species occur per year also in the southern parts of the Barents Sea. Further north there are probably fewer generations. Maturation of $P$. minutus may occur somewhat later in winter in the Barents Sea. In the northern parts of the Barents Sea. the whole cycle is likely to be delayed, leaving room for only one generation per year. In other Arctic localities. $P$. minutus has been found to be mainly annual (Ussing 1938: Digby 1954: Fontaine 1955) or with a life cycle taking from one and a half to two years to complete (Digby 1954: Grainger 1959). However. since a revision of the genus Pseudocalanus has taken place only recently (Frost 1989), several species may have been involved in these studies.

Pseudocalanus females may be reproductively active for up to two months (Corkett \& McLaren 1978). This may account for the presence of adult $P$. minutus females in September and October. Late breeders were also found by Fontaine (1955) in Ungava Bay. Offspring produced this late may have difficulty in surviving under the poor food conditions during winter. Population densities in March are only 5 to $10 \%$ of those in September and October (Table 1 ).

It is clear that Microcalanus pusillus copepodites have a higher degree of maturity later in the season than Pseudocalanus (Figs. 10 and 11). The extent of maturity of $M$. pygmaeus copepodites seems to vary little during the year (Fig. 11D). Perhaps maturation occurs in the adult to a higher degree in this species. as it does in Acartia longiremis (Norrbin 1987) and in the larger copepods (Tande et al. 1985).

\section{Oil sac size}

It is significant that the smallest species in the present study are those which vary the least in fat reserves (Fig. 8). Small copepods such as Microcalamus $(\mathrm{CV}$ and adults of the smaller $M$. pusillus reach a prosome length of about $0.5 \mathrm{~mm}$ ) are likely to be vulnerable to starvation due to relatively large metabolic needs. Smaller organisms have higher weight-specific basal metabolic rates (Kleiber's Law). increasing their needs for a constantly renewed food supply. This may be the prime reason why small copepods have a longer activity period during the year. or, to be precise. why some copepods have undergone an adaptation to a prolonged activity season consisting of a decrease in size. The Microcalanus species are therefore unlikely to abstain from feeding at any
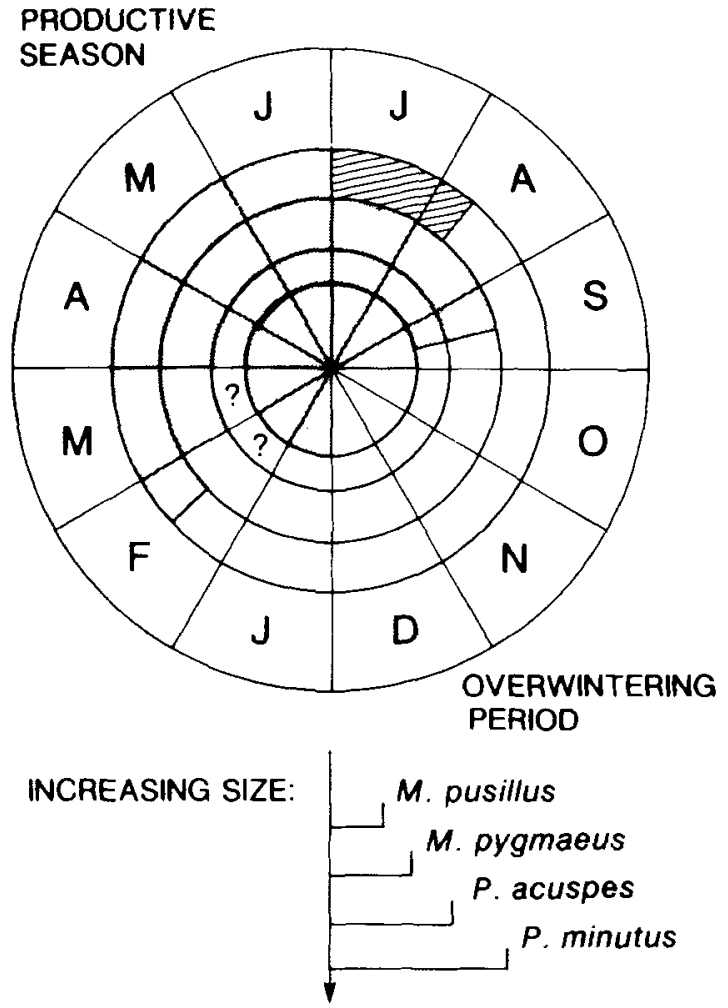

Fig. 12. Possible seasonal cycles in the production period for four species of copepods in the western Barents Sea. The shaded area represents the period of reproduction and developing juveniles in the southern and central parts of the investigated arca. The species are arranged in circles related to prosome length. with the smallest species and longest activity periods in the innermost circles. The diameter of each circle is proportional w the prosome length of the species it represents. The length of the productive season is roughly inversely proportional to size of the copepod specics.

part of the year: their likely food source is detritus and small organisms found in deeper waters. The main distribution of Microcalanus lies in subsurface waters ( 50 to $1200 \mathrm{~m}$. Buchanan \& Sekerak 1982: 200 to $500 \mathrm{~m}$. Sameoto et al. 1986: below $100 \mathrm{~m}$. Norrbin unpubl. data). Fat stores may be an adaptation to short term food variability (Hakansson 1985) rather than a means to early maturation in these species.

The largest seasonal variation in oil sac size is found in Pseudocalamus minutus, the small copcpod species which most resembles the large, herbivorous copepods (Fig. 8B). The fat stores seem to be deleted during the winter, probably contributing both to survival and maturation (Figs. 
$8 \mathrm{~B}$ and 10B). During the productive season, in May, energy appears to be allocated both to maturation and fat stores (Fig. 8B). In $P$. acuspes, on the other hand, the smallest oil sacs are found in May, not in winter. At this time of abundant food, energy seems to be directed into rapid growth and maturation instead of reserves (Fig. 10A). This is consistent with information on the lipid class and fatty acid composition found for this species in Balsfjorden (Norrbin et al. 1990).

In conclusion, the seasonal allocation patterns of these four species reflect other aspects of their ecology. $P$. acuspes is essentially a coastal species, growing quickly when food is abundant, but accumulating energy for winter. Females carry egg-sacs until hatching, implying elements of " $\mathrm{K}$ strategy" (sensu MacArthur \& Wilson 1967). $P$. minutus is even more of a "K-strategist", an oceanic species resembling the large herbivores, with a shorter developing season and a long resting period. Microcalanus spp, are deeper-living species relying on fat storage and detritivory. Eggs of Microcalanus are released directly into the water column (Norrbin unpubl. data). The relationship between copepod size and productive periods has been constructed from the details on stage distribution and gonad maturation in this study and is represented in Fig. 12.

Further investigations into feeding habits, development times and other aspects of the biology of Microcalanus and other little studied species are needed. The tendency to lump species together, which is often done with the smaller species, brings confusion into the interpretation of their life histories and general ecology. The fact that closely related species frequently cooccur, for example, is an observation of great ecological importance, touching upon themes such as the niche theory and hypotheses for sympatric speciation.

Acknowledgements. - I wish to thank S. Diel-Christiansen for inspiration and advice during the early part of the preparation of this manuscript and J. Marks for linguistic corrections. Thanks are also due to the crews of the Norwegian Coastguard vessels and R/V LANCE, to K.S. Tande for access to his 1984 samples, to $L$. Dalsböe for assisting with the dehydration of many stained samples, to $U$. Norrmann for adapting the Basic digitising program to my needs, and to $\mathrm{L}$. Olsen for drawing part of the figures. I am also grateful to my fellow participants in Pro Mare for cooperation and good company on the cruises. This study is part of the Pro Mare programme and was funded by the Norwegian Research Council for Science and the Humanities (NAVF) and the Norwegian Ministry of the Environment.

\section{References}

Brodskii, K. A. 1950: Calanoida of the far eastern seas and polar basin of the USSR. Keys to the fauna of the USSR. No 35. Israel Program for Scientific Translations (Translated from Russian to English, 1967). 440 pp.

Buchanan, R. A. \& Sekerak, A. D. 1982: Vertical distribution of zooplankton in eastern Lancaster Sound and western Baffin Bay, July-October 1978. Arctic 35, 41-55.

Cooney, R. T. \& Coyle, K. O. 1982: Trophic implications of cross-shelf copepod distributions in the southeastern Bering Sea. Mar. Biol, 70, 187-196.

Corkett, C. J. \& McLaren, I. A. 1978: The biology of Pseudocalanus. Adv. Mar. Biol. 15, 1-231.

Digby, P. S. 1954: The biology of the marine planktonic copepods of Scoresby Sound. East Greenland. J. Anim. Ecol. 23, 298-338.

Fontaine, M. 1955: The planktonic copepods (Calanoida, Cyclopoida, Monstrilloida) of Ungava Bay, with special reference to the biology of Pseudocalanus minutus and Calanus finmarchicus. J. Fish. Res. Bd. Can. 12, 858-898.

Frost, B. 1989: A taxonomy of the marine calanoid copepod genus Pseudocalanus. Can. J. Zool. 67, 525-551.

Grainger, E. H. 1959: The annual oceanographic cycle at Igloolik in the Canadian Arctic. 1. The zooplankton and physical and chemical observations. J. Fish. Res. Bd. Can. I6. 453-501.

Hassel, A. 1986: Seasonal changes in zooplankton composition in the Barents Sea, with special reference to Calanus spp. (Copepoda). J. Plankton Res. 8, 329-339.

Hopkins, C. C. E., Tande, K. S., Grönvik, S. \& Sargent, J. R. 1984: Ecological investigations of the zooplankton community of Balsfjorden, northern Norway: An analysis of growth and overwintering tactics in relation to niche and environment in Metridia longa (Lubbock), Calanus finmarchicus (Gunnerus), Thyssanoessa inermis (Kröyer) and T. raschi (M. Sars). J. Exp. Mar. Biol. Ecol. 82, 77-99.

Horner, R. \& Murphy, D. 1985: Species composition and abundance of zooplankton in the near-shore Beaufort sea in winter-spring. Arctic 38, 201-209.

Hăkansson, J. L. 1985. The long and short term feeding condition in field-caught Calanus pacificus, as determined from the lipid content: relationship with phytoplankton pigments in the California current. Dissertation, Univ. of Gothenburg. 92 pp.

MacArthur, R. H. \& Wilson, E. O. 1967. The theory of island biogeography. Princeton University Press, Princeton. 203 pp.

McLaren, I. A. 1969: Population and production ecology of zooplankton in Ogac Lake, a landlocked fiord on Baffin Island. J. Fish. Res. Bd. Can. 26, 1485-1559.

McLaren, I. A. 1974: Demographic strategy of vertical migration by a marine copepod. Am. Nat. 108, 91-102.

Minoda, T. 1967: Seasonal distribution of Copepoda in the Arctic ocean from June to December, 1964. Records of Oceanographic Works in Japan 9(1), 161-168.

Norrbin, M. F. 1987: Overwintering and energetic strategies of marine pelagic copepods in high latitudes. M.Sc. thesis, University of Gothenburg, Gothenburg, Sweden. $101 \mathrm{pp}$.

Norrbin, M. F., Olsen, R.-E. \& Tande, K. S. 1990: Seasonal variation in lipid class and fatty acid composition of two small copepods in Balsfjorden, northern Norway. Mar. Biol. 105, 205-211.

Razouls, S., Nival, S. \& Nival, P. 1987: Development of the genital system in the copepodid stages of the calanoid copepod Temora stylifera Dana. J. Mar. Biol. Ass. U.K. 67.653661 . 


\section{$432 M$. Fredrika Norrbin}

Sameoto. D. Hermann, A. \& Longhurst, A. 1986: Relations between the thermocline meso and microzooplankton. chlorophyll $a$ and primary production distributions in Lancaster Sound. Polar. Biol. 6. 53-61.

Sars, G. O. 1903: An account of the Crustacea of Norway, Vol. IV. Copepoda. Calanoida. Bergen Museum. Bergen.

Tande. K. S. \& Grønvik, S. 1983: Ecological investigations on the zooplankton community of Balsfjorden, northern Norway: sex ratio and gonad maturation cycle in the copepod Metridia longa (Lubbock). J. Exp. Mar. Biol. Ecol. 71. 4354.

Tande, K. S. . Hassel. A. \& Slagstad. D. 1985: Gonad maturation and possible life cycle strategies in Calanus finmarchicus (Gunnerus) and Calanus glacialis (Jaschnov) in the northwestern part of the Barents Sea. Pp. 141-155 in Gray. J. S. \& Christensen. M. E. (eds.): Marine biology of polar regions and the effect of stress on marine organisms. John Wiley \& Sons, Chichester.
Tande. K. S. \& Hopkins, C. C. E. 1981: Ecological invesligations of the zooplankton community of Balsfjorden, Northern Norway: the genital system in Calanus finmarchicus and the role of gonad development in the overwintering strategy. Mar. Biol. 63. 159-164.

Unesco 1968: Zooplankton sampling. Imprimeries Populaires, Genève. 174 pp.

Ussing, H. H. 1938: The biology of some important plankton animals in the fjords of East Greenland. Medd. Grønland 100. 1-108.

Vidal. J. 1971: Taxonomic guides to arctic zooplankton (IV): Key to the calanoid copepods of the central Arctic Ocean. University of Southern California Tech. Rep. No. 5. 128 pp.

Vidal. J. \& Smith. S, L. 1986: Biomass, growth, and development of populations of herbivorous zooplankton in the southeastern Bering Sea during spring. Deep-Sea Res. 33, 523-556 